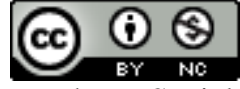

Jurnal Pendidikan Ilmu Pengetahuan Sosial Indonesia is licensed under

A Creative Commons Attribution-Non Commercial 4.0 International License.

\title{
ANALISIS SIKAP PEDULI LINGKUNGAN PADA SISWA KELAS XI IPS SMA DI KOTA PONTIANAK
}

\author{
Nur Meily Adlika \\ Universitas Tanjungpura,Pontianak, Indonesia \\ E-mail: nurmeilyadlika@fkip.untan.ac.id
}

\begin{abstract}
Abstrak. Artikel ini merupakan penelitian yang dilaksanakan pada tahun pelajaran 2019/2020. Penelitian ini bertujuan untuk mengetahui sikap peduli lingkungan pada siswa kelas XI IPS di SMA Kota Pontianak. Penelitian ini merupakan penelitian deskriptif dengan pendekatan kuantitatif. Populasi dalam penelitian ini adalah siswa kelas XI IPS di SMA N 3 dan MAN 2 Kota Pontianak. Teknik pengumpulan data menggunakan observasi, angket serta studi literatur dan dokumentasi. Analisis data menggunakan pengolahan data dan penyajian data dengan perhitungan persentase. Teknik uji persyaratan analisis menggunakan uji validitas dan reliabilitas dengan bantuan aplikasi SPSS. Hasil penelitian menunjukkan bahwa sikap peduli lingkungan siswa kelas XI IPS di SMA N 3 termasuk kategori baik sebesar 71,50\% sedangkan sikap peduli lingkungan siswa kelas XI IPS di MAN 2 termasuk kategori baik sebesar 71,34\%.Berdasarkan kesimpulan, peneliti menyarankan bagi guru SMA agar lebih mengintegrasikan materi lingkungan pada mata pelajarannya untuk meningkatkan pengetahuan siswa tentang kebersihan lingkungan dan dapat membentuk sikap peduli lingkungan pada siswa. Bagi orang tua diharapkan dapat membimbing anaknya dalam perilaku sehari-hari untuk mengingatkan dan mengajarkan membuang sampah pada tempatnya, hal ini bertujuan untuk membentuk sikap peduli anak terhadap lingkungannya.Bagi pemerintah diharapkan agar lebih giat memberikan sosialisasi tentang kebersihan lingkungan kepada sekolah-sekolah maupun juga masyarakat agar mengetahui betapa pentingnya kebersihan lingkungan bagi kelangsungan hidup sehari-hari.
\end{abstract}

Keywords: Sikap, Lingkungan, Peduli Lingkungan

\section{Pendahuluan}

Dalam skala global, masalah lingkungan hidup merupakan awal dari sebagian besar krisis yang melanda dunia. (Sachs, 2009). Berbagai masalah yang kita hadapi saat ini yaitu perubahan iklim, pencemaran lingkungan, kelangkaan air bersih, rendahnya kesuburan lahan dan menurunnya sumber daya kelautan dan perikanan. Hal ini disebabkan banyaknya limbah pabrik, asap kendaran bermotor, penggunaan bahan kimia pembersih rumah, pengusir seranga, dan mesin pendingin yang menghasilkan akumulasi gas-gas sehingga memberntuk lapisan yang disebut dengan gas rumah kaca. Adanya lapisan gas ini menghalangi pantulan dari sinar matahari keluar dari atmosfer bumi, dan menangkap sinar matahari yang mengakibatkan peningkatan suhu permukaan bumi.

Adanya interaksi antara manusia dan lingkungan juga telah banyak menimbulkan berbagai kerusakan pada lingkungan. Suseno (Wilujeng, 2011:6) mengatakan banyak kerusakan lingkungan yang disebabkan oleh sikap teknokratis manusia, yaitu sikap manusia yang memandang lingkungan sebatas objek penguasaan kebutuhan. Sikap ini dapat ditemukan pada perusahaan yang membakar hutan dan terlibat dalam berbagai degradasi lahan dengan alasan penghematan biaya operasional. Sikap ini lebih mengutamakan keuntungan ekonomi jangka pendek daripada kelestarian lingkungan.

Sebagai bagian dari komunitas dunia, Indonesia dan khususnya Kota Pontianak tidak terlepas dari permasalahan lingkungan. Menurut data DLH Kota Pontianak, Pontianak bisa menghasilkan 400 ton sampah dalam sehari. Sampah ini didominasi oleh sampah rumah tangga. Kepala Dinas Lingkungan Hidup Kota Pontianak, Tinorma menjelaskan rendahnya kesadaran masyarakat terhadap pengelolaan sampah berdampak pada penumpukan sampah di TPS. Jika dibiarkan berlarut-larut, hal itu dapat merusak estetika kota. Dampak yang ditimbulkan akibat penumpukan sampah ialah bau yang menyengat, mengganggu kesehatan dan merusak estetika kota. Bahkan, kota terlihat kumuh saat terjadi penumpukan sampah di TPS pinggir jalan (http://kalbarupdates.com/kalbar/metropolis/pemkotpontianak-pinta-warga-kurangiproduksi-sampah/ diunduh pada tanggal 04 Juli 2019 12:08).

Kerusakan lingkungan yang meluas pada saat ini semakin menegaskan akan pentingnya sikap peduli lingkungan, namun disayangkan pendidikan lingkungan hidup yang diharap mampu membentuk sikap peduli lingkungan belum sesuai tujuan. Muhaimin (2015:49) mengatakan bahwa penyebab kegagalannya disebabkan karena pendekatan pembelajaran yang digunakan pendidik dalam ecopedagogi kurang 
mengeksplorasi siswa untuk menemukan informasi, menganalisis, dan membuat keputusan berdasarkan inkuiri, sehingga materi yang diberikan tidak menjadi perilaku yang ditampilkan sehari-hari.

Salah satu solusi yang dapat dilakukan untuk mencgah terjadinya kerusakan lingkungan yaitu pendidikan lingkungan hidup dengan memberikan motivasi pentingnya memiliki sikap peduli lingkungan baik dalam bentuk sosialisasi pada masyarakat di luar sekolah maupun pendidikan linngkungan yang diintegrasikan dalam kurikulum sekolah. Karena lingkungan akan berpengaruh terhadap perilaku manusia. Sikap peduli lingkungan dapat dibiasakan dari hal yang terkecil, misalnya membuang sampah pada tempatnya, memisahkan sampah organik dan non organik, menanam pohon, tidak berlebihan dalam penggunaan sumber daya alam dan menjaga kebersihan lingkungan (Hamzah, 2013:3)

Oleh karena itu jalur pendidikan merupakan sarana tepat untuk membangun masyarakat yang menerapkan prinsip keberlanjutan dan etika lingkungan. Jalur pendidikan yang bisa ditempuh mulai dari tingkat Taman Kanan-kanak sampai PerguruanTinggi. Tujuannya adalah mngembangkan warga negara yang memilki pengetahuan tentang lingkungan biofisik dan masalah yang berkaitan. Selain itu juga agar menumbuhkan kesadaran agar terlibat secara efektif dalam tindakan menuju pembangunan masa depan yang lebih baik, dapat dihuni dan membangkitkan motivasi untuk melakukannya.

Siswa SMA merupakan peserta didik yang sudah mulai diberikan berbagai macam tanggung jawab. Posisinya dalam sepuluh sampai dua puluh tahun mendatang, bahwa merekalah yang menjadi pemegang kebijakan, pengusaha dan penduduk yang menentukan arah pengelolaan lingkungan hidup. Jika setaip individu sudah tertanam sikap peduli lingkungan maka bukan hal yang mustahil masalah lingkungan hidup sudah tidak ada lagi.

\section{KAJIAN TEORI}

Sikap peduli lingkungan dapat dipahami sebagai perasaan orang yang peduli terhadap kelestarian lingkungan. Sikap ini tidak dapat diketahui secara langsung, tetapi melalui perilaku yang dilakukan. Misalkan membuang sampah pada tempatnya, mencegah penebangan liar dan sebagainya. Sikap ini sangat diperlukan karena telah banyak lingkungan yang rusak akibat pemanfaatan lingkungan yang tidak baik. Kondisi seperti ini dapat ditemukan pada kehidupan masyarakat di kota-kota besar salah satunya di Kota Pontianak.

Sikap peduli lingkungan pada siswa merupakan sebuah perubahan perilaku yang ditunjukkan oleh pemahaman, perasaan dan kecenderungan untuk mengaplikasikan pengetahuan lingkungan yang dimiliki melalui tindakan yang berdampak positif bagi lingkungan. Seperti menjaga kebersihan dan berusaha mencegah dampak buruk yang berpotensi merusak lingkungan.

Menurut Van Liere Dunlap (Andromeda, 2009:74), indikator sikap peduli lingkungan terdiri dari limma bagian yang dikonsepsikan dengan nama New Ecological Paradigm(NEP), yang terdiri dari batasan untuk tumbuh, pandangan anti antrophosentris, kemungkinan krisis lingkungan, dan penolakan terhadap perilaku sewenangwenang terhadap lingkungan

\section{METODE PENELITIAN}

Penelitian ini merupakan penelitian deskriptif dengan pendekatan kuantitatif. Populasi dalam penelitian ini adalah siswa kelas XI IPS di SMA N 3 dan MAN 2 Kota Pontianak. Teknik pengumpulan data menggunakan observasi, angket serta studi literatur dan dokumentasi. Analisis data menggunakan pengolahan data dan penyajian data dengan perhitungan persentase. Teknik uji persyaratan analisis menggunakan uji validitas dan reliabilitas dengan bantuan aplikasi SPSS.

\section{HASIL DAN PEMBAHASAN}

Data sikap peduli lingkungan peserta didik diperoleh dari hasil kuesioner berbentuk skala likert dengan 15 pernyataan dan 4 pilihan jawaban. Skor penilaian untuk masing-masing butir pernyataan adalah 4 untuk skor yang menjawab sangat setuju, 3 setuju, 2 tidak setuju dan 1 untuk skor yang menjawab sangat tidak setuju. Dari penskoran tersebut diperoleh total skor dari masing-masing butir pernyataan. Hasil tes pengetahuan lingkungan peserta didik tersebut, kemudian dipresentasekan untuk diketahui kategorinya sesuai nilai indeksnya.

\section{a. SMA N 3 Pontianak}

Tabel 1. Hasil Tabulasi Data Sikap Peduli Lingkungn SMA N 3 Kelas XI IPS 2

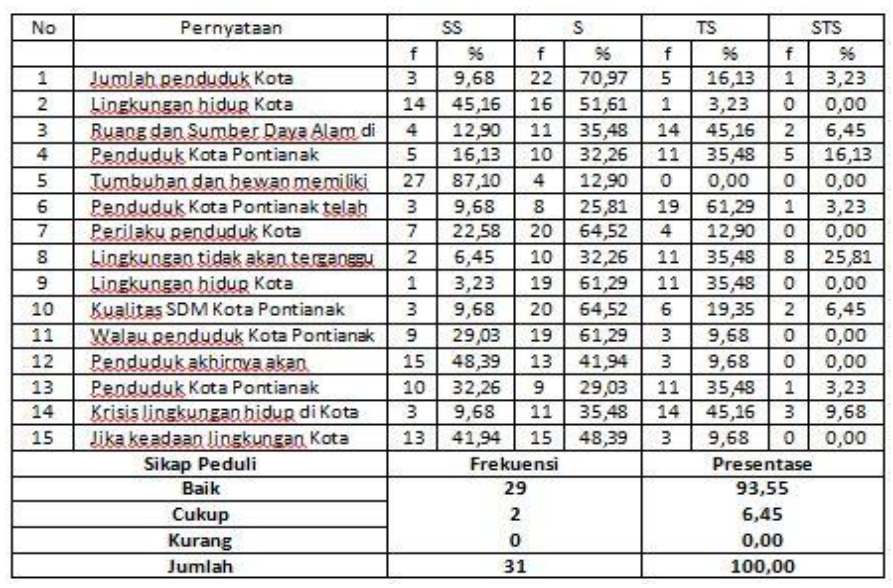

Hasil tabulasi data sikap peduli lingkungan di SMA N 3 kelas XI IPS 2 diperoleh kategori baik sebanyak 29 responden dengan presentase 93,55\%. Sedangkan kategori cukup sebanyak 2 responden presentase $6,45 \%$. Hal inidapat dilihat dari jawaban responden yang menyatakan sangat setuju untuk pertanyaan seperti nomor $2(45,16 \%)$, nomor $5(87,10 \%)$ dan nomor $12(48,39 \%)$. Responden yang menyatakan setuju pada nomor $1(70,97)$, nomor $7(64,52 \%)$, dan nomor $10(64,52 \%)$. 
Responden yang menyatakan tidak setuju pada nomor 3 $(45,16 \%)$, nomor $6(61,29 \%)$, dan nomor $14(45,16 \%)$. Sedangkan responden yang menjawab sangat tidak setuju contohnya pada nomor $3(6,45 \%)$, nomor $4(16,13 \%)$, dan nomor $8(25,81 \%)$.

Tabel 2.Hasil Tabulasi Data Sikap Peduli Lingkungan SMA N 3 Kelas XI IPS 3

\begin{tabular}{|c|c|c|c|c|c|c|c|c|c|}
\hline No & Pernyataan & \multicolumn{2}{|c|}{ ss } & \multicolumn{2}{|r|}{$s$} & \multicolumn{2}{|c|}{ TS } & \multicolumn{2}{|c|}{ STS } \\
\hline & & $f$ & $\% 6$ & $f$ & 96 & $f$ & 96 & $f$ & $\%$ \\
\hline 1 & Jumlah penduduk Kota & 5 & 16,67 & 17 & 56,67 & 6 & 20,00 & 2 & 6,67 \\
\hline 2 & Lisgkungan hidup Kota & 18 & 60,00 & 12 & 40,00 & 0 & 0,00 & 0 & 0,00 \\
\hline 3 & Buang dan Sumber Daya Alam di & 4 & 13,33 & 12 & 40,00 & 11 & 36,67 & 3 & 10,00 \\
\hline 4 & Penduduk Kota Pontianak & 7 & 23,33 & 14 & 46,67 & 4 & 13,33 & 5 & 16,67 \\
\hline 5 & Tumbuhan dan hewan memiliki & 29 & 96,67 & 1 & 3,33 & 0 & 0,00 & 0 & 0,00 \\
\hline 6 & Penduduk Kota Pontianak telab & 3 & 10,00 & 3 & 10,00 & 17 & 56,67 & 7 & 23,33 \\
\hline 7 & Perilaku penduduk Kota & 2 & 6,67 & 15 & 50,00 & 10 & 33,33 & 3 & 10,00 \\
\hline 8 & Lingkungan tidak akan te rganguy & 4 & 13,33 & 7 & 23,33 & 18 & 60,00 & 1 & 3,33 \\
\hline 9 & Lingkungan hidug Kota & 2 & 6,67 & 18 & 60,00 & 8 & 26,67 & 2 & 6,67 \\
\hline 10 & Kualitas SDM Kota Pontianak & 9 & 30,00 & 13 & 43,33 & 5 & 16,67 & 3 & 10,00 \\
\hline 11 & Walau penduduk Kota Pontianak & 7 & 23,33 & 23 & 76,67 & 0 & 0,00 & 0 & 0,00 \\
\hline 12 & Penduduk akhicrua akan & 10 & 33,33 & 18 & 60,00 & 2 & 6,67 & 0 & 0,00 \\
\hline 13 & Penduduk Kota Pontianak & 0 & 0,00 & 8 & 26,67 & 18 & 60,00 & 4 & 13,33 \\
\hline 14 & Krisis lingkungan hidur di Kota & 0 & 0,00 & 6 & 20,00 & 21 & 70,00 & 3 & 10,00 \\
\hline 15 & Jika keadaan lingkungan Kota & 11 & 36,67 & 13 & 43,33 & 2 & 6,67 & 4 & 13,33 \\
\hline & Sikap Peduli & \multicolumn{4}{|c|}{ Frekuensi } & \multicolumn{4}{|c|}{ Presentase } \\
\hline & Baik & \multirow{2}{*}{\multicolumn{4}{|c|}{$\begin{array}{c}29 \\
1\end{array}$}} & \multicolumn{4}{|c|}{96,67} \\
\hline & Cukup & & & & & \multirow{2}{*}{\multicolumn{4}{|c|}{$\begin{array}{l}3,33 \\
0,00\end{array}$}} \\
\hline & Kurang & \multicolumn{4}{|c|}{0} & & & & \\
\hline & Jumlah & \multicolumn{4}{|c|}{30} & \multicolumn{4}{|c|}{100,00} \\
\hline
\end{tabular}

Hasil tabulasi data sikap peduli lingkungan di SMA N 3 kelas XI IPS 3 diperoleh kategori baik sebanyak 29 responden dengan presentase $96,67 \%$. Sedangkan kategori cukup sebanyak 1 responden presentase 3,33\%. Hal ini dapat dilihat dari jawaban responden yang menyatakan sangat setuju untuk pertanyaan seperti nomor $2(60,00 \%)$, nomor $5(96,67 \%)$ dan nomor $15(36,67 \%)$. Responden yang menyatakan setuju pada nomor $1(56,67)$, nomor $9(60,00 \%)$, dan nomor $11(76,67 \%)$. Responden yang menyatakan tidak setuju pada nomor 6 $(56,67 \%)$, nomor $13(60,00 \%)$, dan nomor $14(70,00 \%)$. Sedangkan responden yang menjawab sangat tidak setuju contohnya pada nomor $4(16,67 \%)$, nomor $6(23,33 \%)$, dan nomor $15(13,33 \%)$.

b. MAN 2 Pontianak

Tabel 3. Hasil Tabulasi Data Sikap Peduli Lingkungan MAN 2 Kelas XI IPS 1

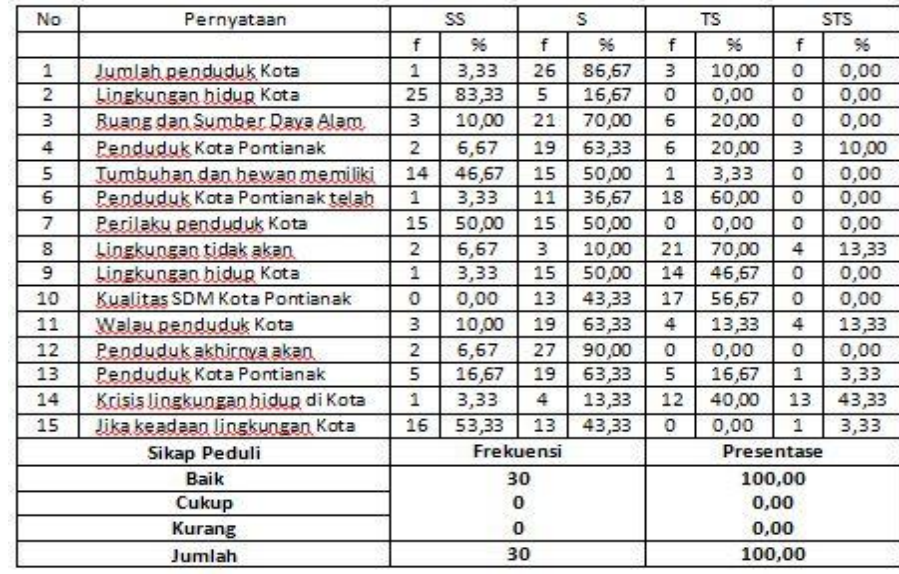

Hasil tabulasi data sikap peduli lingkungan di MAN 2 kelas XI IPS 1 diperoleh kategori baik sebanyak 30 responden dengan presentase $100 \%$.Sedangkan kategori cukup sebanyak 0 responden presentase $0 \%$. Hal ini dapat dilihat dari jawaban responden yang menyatakan sangat setuju untuk pertanyaan seperti nomor $2(83.33 \%)$, nomor $7(50,00 \%)$ dan nomor 15 $(53,33 \%)$. Responden yang menyatakan setuju pada nomor 1 $(86,67)$, nomor 3 (70,00\%), dan nomor 13 (63,33\%). Responden yang menyatakan tidak setuju pada nomor 6 $(60,00 \%)$, nomor $9(46,67 \%)$, dan nomor $10(56,67 \%)$. Sedangkan responden yang menjawab sangat tidak setuju contohnya pada nomor $4(10,00 \%)$, nomor $11(13,33 \%)$, dan nomor $14(43,33 \%)$.

Tabel 4. Hasil Tabulasi Data Sikap Peduli Lingkungan MAN 2 Kelas XI IPS 2

\begin{tabular}{|c|c|c|c|c|c|c|c|c|c|}
\hline No & Pernyataan & \multicolumn{2}{|c|}{ ss } & \multicolumn{2}{|r|}{$s$} & \multicolumn{2}{|c|}{ TS } & \multicolumn{2}{|c|}{ STS } \\
\hline & & $f$ & 96 & $f$ & $\%$ & $f$ & $\%$ & $f$ & $\%$ \\
\hline 1 & Jumlah genduduk Kota & 0 & 0,00 & 25 & 80,65 & 6 & 19,35 & 0 & 0,00 \\
\hline 2 & Lingkungan hidug Kota & 15 & 48,39 & 16 & 51,61 & 0 & 0,00 & 0 & 0,00 \\
\hline 3 & Buang dan Sumber Dava Alam di & 3 & 9,68 & 16 & 51,61 & 11 & 35,48 & 1 & 3,23 \\
\hline 4 & Penduduk Kota Pontianak & 10 & 32,26 & 7 & 22,58 & 12 & 38,71 & 2 & 6,45 \\
\hline 5 & Tumbuhan dan hewan memiliki & 27 & 87,10 & 4 & 12,90 & 0 & 0,00 & 0 & 0,00 \\
\hline 6 & Penduduk Kota Pontianak telab & 2 & 6,45 & 10 & 32,26 & 13 & 41,94 & 6 & 19,35 \\
\hline 7 & Perilaku genduduk Kota & 9 & 29,03 & 18 & 58,06 & 4 & 12,90 & 0 & 0,00 \\
\hline 8 & Lingkungan tidak akan & 4 & 12,90 & 3 & 9,68 & 18 & 58,06 & 6 & 19,35 \\
\hline 9 & Lingkungan hidug Kota & 6 & 19,35 & 18 & 58,06 & 7 & 22,58 & 0 & 0,00 \\
\hline 10 & Kualitas SDM Kota Pontianak & 2 & 6,45 & 16 & 51,61 & 13 & 41,94 & 0 & 0,00 \\
\hline 11 & Walay Renduduk Kota & 14 & 45,16 & 14 & 45,16 & 3 & 9,68 & 0 & 0,00 \\
\hline 12 & Penduduk akbicoras akan. & 18 & 58,06 & 10 & 32,26 & 2 & 6,45 & 1 & 3,23 \\
\hline 13 & Penduduk Kota Pontianak & 2 & 6,45 & 13 & 41,94 & 6 & 19,35 & 10 & 32,26 \\
\hline 14 & Kcisis lingkungan hidur di Kota & 3 & 9,68 & 6 & 19,35 & 20 & 64,52 & 2 & 6,45 \\
\hline 15 & lika keadaan lingkungan Kota & 9 & 29,03 & 9 & 29,03 & 10 & 32,26 & 3 & 9,68 \\
\hline & Sikap Peduli & \multicolumn{4}{|c|}{ Frekuensi } & \multicolumn{4}{|c|}{ Presentase } \\
\hline & Baik & \multirow{2}{*}{\multicolumn{4}{|c|}{$\begin{array}{c}31 \\
0\end{array}$}} & \multirow{2}{*}{\multicolumn{4}{|c|}{$\begin{array}{c}100,00 \\
0,00\end{array}$}} \\
\hline & Cukup & & & & & & & & \\
\hline & Kurang & \multicolumn{4}{|c|}{0} & \multicolumn{4}{|c|}{0,00} \\
\hline & Jumlah & \multicolumn{4}{|c|}{31} & \multicolumn{4}{|c|}{100,00} \\
\hline
\end{tabular}

Hasil tabulasi data sikap peduli lingkungan di MAN 2 kelas XI IPS 2 diperoleh kategori baik sebanyak 31 responden dengan presentase $100 \%$. Sedangkan kategori cukup sebanyak 0 responden presentase $0 \%$. Hal ini dapat dilihat dari jawaban responden yang menyatakan sangat setuju untuk pertanyaan seperti nomor $2(48.39 \%)$, nomor $5(87,10 \%)$ dan nomor 12 $(58,06 \%)$. Responden yang menyatakan setuju pada nomor 1 $(80,65)$, nomor $3(51,61 \%)$, dan nomor $7 \quad(58,06 \%)$. Responden yang menyatakan tidak setuju pada nomor 6 $(41,94 \%)$, nomor $8(58,06 \%)$, dan nomor $14(64,52 \%)$. 
Sedangkan responden yang menjawab sangat tidak setuju contohnya pada nomor $6(19,35 \%)$, nomor $8(19,35 \%)$, dan nomor $13(32,26 \%)$.

\section{KESIMPULAN}

Berdasarkan hasil penelitian dan pembahasan yang dapat diambil kesimpulan bahwa sikap peduli lingkungan peserta didik di SMA N 3 termasuk kategori baik sebesar 71,50\% sedangkan sikap peduli lingkungan peserta didik di MAN 2 termasuk kategori baik sebesar 71,34\%.

\section{DAFTAR PUSTAKA}

Andromeda. M.F.K. (2009): Relevansi Status Sosial Ekonomi Terhadap Kepedulian Lingkungan Hidup Dalam Konteks Indonesia Sebagai Negara Berkembang. Jakarta. Universitas Indonesia

Hamzah, S. 2013. Pendidikan Lingkungan. PT.Refika Aditama. Bandung.

Muhaimin. (2015): Membangun Kecerdasan Ekologis. Bandung. Alfabeta

Sachs, Jeffrey. 2009. Common Wealth: Econimic for a Crowde Planet.

Wilujeng, Sri Rahayu. 2003. Mencari Landasan Etis Bagi Upaya Membudayakan Pengelolaan Lingkungan Yang Bertanggung Jawab. Semarang. Universitas Diponegoro.

(http://kalbarupdates.com/kalbar/metropolis/pemkotpontianak-pinta-warga kurangiproduksi-sampah/ diunduh pada tanggal 04 Juli 2019 12:08). 